\title{
Pegada Hídrica como Indicador de Sustentabilidade Ambiental ${ }^{1}$
}

\section{Water Footprint as Indicator of Environmental Sustainability}

\author{
Kettrin Farias Bem Maracajá \\ Doutoranda em Recursos Naturais - Programa de Pós-Graduação em Recursos Naturais (UFCG) \\ Professora da Universidade Federal do Rio Grande do Norte, Departamento de Ciências Sociais e Humanas/Turismo \\ Endereço: Rua, Aprígio Veloso, 882, Bairro Universitário, CEP: 58.429-140, Campina Grande, PB, Brasil. \\ Fone: (83) 2101-1000,e-mail: kettrin@gmail.com \\ Vicente de Paulo Rodrigues da Silva \\ Professor da Universidade Federal de Campina Grande \\ Centro de Tecnologia e Recursos Naturais, Unidade Acadêmica Ciências Atmosféricas \\ Endereço: Rua, Aprígio Veloso, 882, Bairro Universitário, CEP: 58.429-140, Campina Grande, PB, Brasil. \\ Fone: (83) 2101-1000, e-mail: vicente@dca.ufcg.edu.br \\ José Dantas Neto
Doutor e Professor do Programa de Pós-Graduação em Recursos Naturais (Mestrado e Doutorado)
Universidade Federal de Campina Grande
Endereço: Rua, Aprígio Veloso, 882, Bairro Universitário, CEP: 58.429-140, Campina Grande, PB, Brasil.
Fone: (83) 2101-1000, e-mail: zedantas@dca.ufcg.edu.br \\ Lincoln Eloi de Araújo \\ Doutor em Recursos Naturais e Professor do Departamento de Engenharia e Meio Ambiente/Ecologia \\ Universidade Federal da Paraíba \\ Endereço: Rua da Mangueira S/N, CEP: 58.297-000 - Rio Tinto, PB - Brasil \\ Telefone: (83) 3291-1528, e-mail: lincolneloi@yahoo.com.br
}

RESUMO

O conceito de pegada hídrica tem sido recentemente introduzido como um importante indicador do consumo de água humano, na tentativa de minimizar os impactos ambientais. Esse trabalho aborda o conceito da pegada hídrica como um indicador de sustentabilidade, com vistas o uso racional dos recursos hídricos. Nos últimos anos, a escassez de alguns recursos naturais vem sendo bastante discutido em todo o mundo e quanto à água a preocupação é ainda maior em face do uso desordenado na irrigação, bem como pela poluição da água potável através da indústria e agricultura. Partindo dessa análise, a pegada hídrica surge como um indicador de sustentabilidade da água doce em seus diferentes tipos de consumo para que seja utilizada de forma consciente. Com base na revisão da literatura sobre o tema abordado, conclui-se que para a redução da pegada hídrica se deve tomar medidas de controle do uso direto e indireto da água doce principalmente na agricultura irrigada.

Palavras-chave: Indicador de consumo de água. Escassez de água. Sustentabilidade.

\section{ABSTRACT}

The concept of water footprint has been recently introduced as an important indicating of human water consumption in an attempt to minimize environmental impacts. This paper discusses the concept of water footprint as an indicating of sustainability, aiming the rational use of water resources. In recent years, the scarcity of some natural resources has been widely discussed around the world and if the water is even greater concern in the face of the disordered use in irrigation and for drinking water by industry and agriculture. From this analysis, the water footprint appears as an indicator of sustainability of fresh water in its different types of consumption to be used consciously. Based on a review of the literature about the subject, the results show that to reduce the water footprint measures should be taken of the direct and indirect use of water primarily in irrigated agriculture.

Keywords: Indicating of water consumption. Water scarcity. Sustainability.

\footnotetext{
${ }^{1}$ Artigo recebido em 26.06.2012. Avaliado por pares (blind review). Recomendado para publicação em 25.07.2012 por José Ribamar Marques de Carvalho (Editor Científico). Publicado em 07.08.2012.
} 


\section{INTRODUÇÃO}

As últimas décadas marcaram um período de grande crescimento da população mundial, com significativo impacto econômico e ambiental, principalmente pela produção de alguns produtos tidos como sendo de "luxo" (HOEKSTRA, 2010). Esses produtos além de não serem prioritários necessitam de grande volume de água para serem produzidos. Deste modo, observa-se que a redução dos recursos naturais está ligada ao consumo exagerado de bens de consumo que se torna cada vez mais crítico em face do crescimento populacional.

A tentativa de mensurar a ausência de equilíbrio ambiental entre a humanidade e os recursos naturais leva a inclusão de indicadores de sustentabilidade como ferramenta importante na avaliação do uso correto desses recursos (ERCIN; ALDAYA; HOEKSTRA et al., 2011). Neste contexto, a pegada hídrica surge como um indicador de sustentabilidade ambiental. A pegada hídrica $(\mathrm{PH})$ é definida como sendo o volume de água total usada durante a produção e consumo de bens e serviços, bem como o consumo direto e indireto da água em todo o processo de produção para a quantificação do total de água em toda a cadeia produtiva (HOESKSTRA, 1998). A sustentabilidade de uma pegada hídrica depende de fatores climáticos e hídricos de uma região. Uma localidade com grande fluxo de água tem uma pegada hídrica diferente daquela com escassez de água.

Para Hoekstra e Chapagain $(2007,2008)$, o uso da água doce está totalmente relacionado aos problemas de escassez e poluição, ocorrendo isso principalmente pelo grande uso de pesticidas na agricultura e pelo lançamento de poluentes industriais lançados no ar e na água. Constata-se ainda que os consumidores finais, revendedores, comerciantes e todos os tipos de empresas que operam ao longo da cadeia produtiva de bens de consumo continuam fora do alcance das políticas governamentais destinadas a atenuar a escassez de água e a poluição. $\mathrm{O}$ uso da água no mundo está ligado principalmente ao consumo final dos consumidores (HOKESTRA; CHAPAGAIN, 2008).

No ano de 1993 o britânico John Anthony Allan criou o conceito de "água virtual", apresentando-se, inclusive, a metodologia de cálculo da água efetivamente envolvida nos processos produtivos. Esse conceito levar em consideração toda a água envolvida na cadeia de produção, bem como as características específicas da região produtora e as características ambientais e tecnológicas (CARMO et al., 2007). Nesse aspecto, o conceito de pegada hídrica surge como um indicador do consumo de água de pessoas e produtos em diversas partes do mundo (VAN OEL et al., 2009; ZHAO et al., 2009; ROMAGUERA et al., 2010; FENG et $a l ., 2011)$. A PH também expressa o volume de água total usada no consumo direto e indireto no processo de produção para um indivíduo, empresa ou nação. A determinação da PH é capaz de quantificar o consumo de água total ao longo da cadeia produtiva (YANG YU et al., 2010). A maioria do uso de água ocorre na produção agrícola, destacando também um número significativo de volume de água consumida e poluída derivada dos setores industriais e domésticos.

Muitos produtos são colocados no mercado mundial a um preço que não incluir adequadamente o custo da água contida no produto; sendo, portando, tarifado de forma errada. Isso leva as situações em que algumas regiões acabam tendo que exportar produtos, na forma de água virtual, o que torna os recursos hídricos cada vez mais escassos (HOEKSTRA; HUNG, 2005). 
Esse trabalho objetiva analisar o conceito da a pegada hídrica como um indicador de sustentabilidade ambiental, considerando-se o uso da água doce na agricultura irrigada, indústria e consumo doméstico.

\section{PROCEDIMENTOS METODOLÓGICOS}

Esta pesquisa caracteriza-se por ser bibliográfica pelo fato de explicar e discutir um assunto com base em referências bibliográficas publicadas em livros, periódicos, sites, etc. Com isso, pretende-se aprimorar os conhecimentos científicos através de uma reflexão crítica sobre a problemática dos recursos hídricos. Nesse contexto, o conceito da pegada hídrica surge como uma alternativa de mensurar o consumo da água doce e, assim, constituí-se num indicador de sustentabilidade ambiental capaz de expressar o consumo de água doce de pessoas, comunidades, estados e países.

Para uma melhor análise do objeto de estudo do tema abordado nesse artigo, foram considerados também os princípios básicos e metodológicos da pegada hídrica a partir do manual publicado pela Water Footprint Network (HOEKSTRA et al., 2009). A metodologia da pegada hídrica, em resumo, refere-se a construção do conhecimento do uso da água escondida nos produtos, ajudando-se, assim, a compreender o caráter global de água doce e a sua quantificação nos consumos direto e indiretos. A pegada hídrica, neste caso, servirá como instrumento para indicar a sustentabilidade hídrica de modo que possa ocorrer maior conscientização do uso de água doce no planeta por parte da sociedade organizada.

\section{FUNDAMENTAÇÃO TEÓRICA}

\subsection{Histórico sobre a pegada hídrica}

A retirada de água doce global aumentou quase sete vezes no século passado e esse valor deve crescer cada dia mais devido o aumento populacional, bem como as diferentes mudanças de hábitos alimentares e de consumo (GLEICK, 2000). Desse modo, o volume de água de superfícies líquidas (rios lagos, etc) em determinado período não são totalmente disponíveis em face da evaporação, principalmente em regiões com alta demanda atmosférica, tal como em áreas áridas e semiáridas (SILVA et al., 2006). O aumento da demanda da água doce para o consumo humano e para a irrigação é outro problema que o mundo vem enfrentando atualmente (PERRY, 2007).

A pegada hídrica surgiu no ano de 2002 durante uma reunião de peritos sobre o comércio internacional de água virtual, em Delf, na Holanda pelo precursor Arjen Hokestra. A pegada hídrica tem como premissa metodológica diminuir os efeitos da escassez de água que priva milhares de pessoas em todo o mundo, de modo que ocorra uma melhor gestão hídrica desse recurso evitando, assim, a exploração em localidades mais escassas, direcionando o consumo para regiões de maior abundância de água doce.

Deste modo, para facilitar o entendimento sobre essa temática se torna primordial mencionar que a maior parte da água utilizada pelos seres humanos vem dos produtos que elas utilizam e não do consumo diário como a maioria pensa. Cabe destacar que nessa análise são levados em consideração os litros de água que são consumidos por todos, desde a utilização 
de 15.500 litros para produzir $1 \mathrm{~kg}$ de carne bovina e aos 130 litros de água para produzir uma xícara de café.

A sustentabilidade da pegada hídrica está diretamente relacionada com a disponibilidade de água da região considerada, que pode variar entre cidades, estados e países. É importante considerar o fluxo de água virtual entre diferentes países. Isso implica que países com escassez de água tem alto consumo de água virtual contida nos produtos consumidos por esse país. O conceito de água virtual leva em consideração a água utilizada na fabricação do produto desde o consumo de água da produção agrícola até processo de manufatura.

Os estudos de Hoekstra e Chapagain (2007) mostram que a agricultura é o setor com maior utilização de água doce, correspondendo a $70 \%$ do consumo de água total do planeta. Por outro lado, o volume gasto gasto no setor industrial é de $22 \%$ e para o uso doméstico é de $8 \%$. Assim, o tamanho da pegada hídrica mundial é determinado pelo consumo de alimentos, uso de água no consumo industrial e doméstico, sendo de $1.243 \mathrm{~m}^{3} /$ ano per capita por habitante (HOEKSTRA; CHAPAGAIN, 2007). De acordo com o Figura 1 a pegada hídrica mundial da agricultura é de $6.390 \times 10^{9} \mathrm{~m}^{3} / \mathrm{ano}$, a doméstica é de $344 \times 10^{9} \mathrm{~m}^{3} /$ ano e a da indústria $716 \times 10^{9} \mathrm{~m}^{3} /$ ano. Portanto, o setor produtivo que mais utiliza a água é a agricultura irrigada.

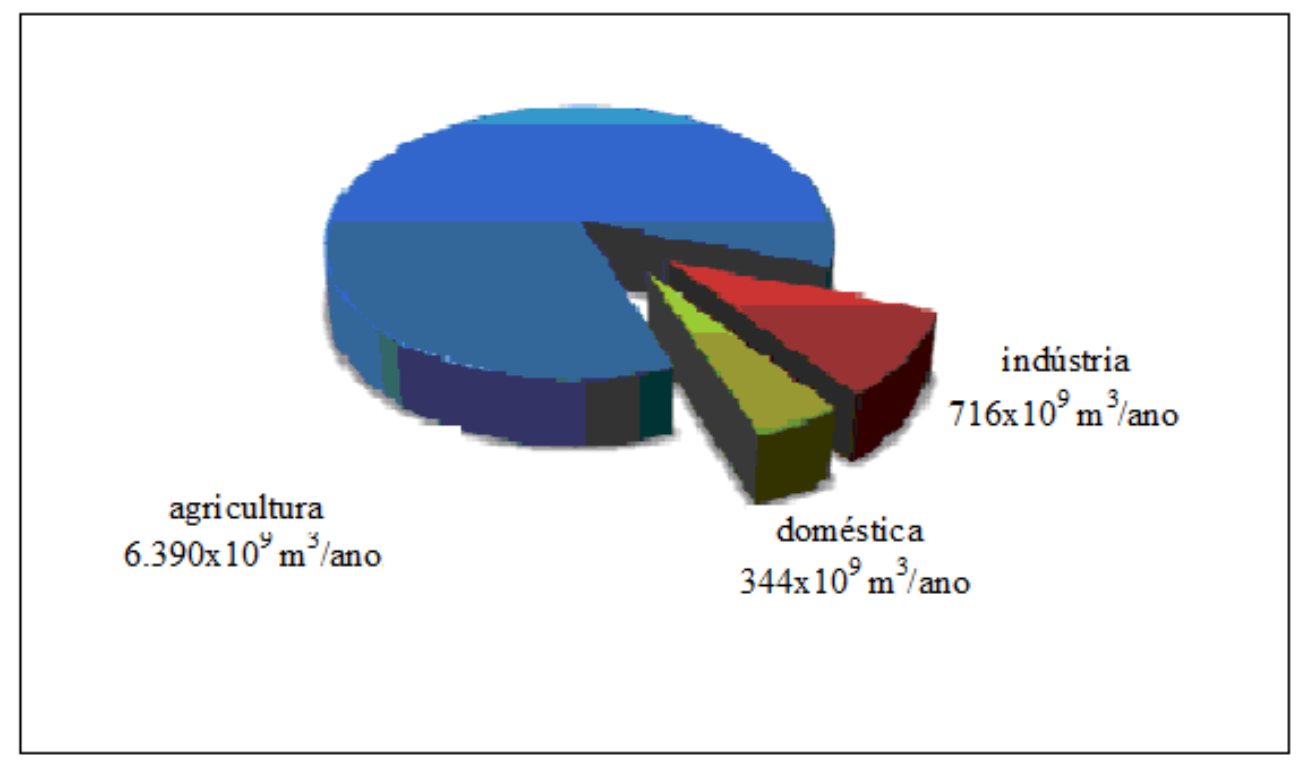

Figura 1. Pegada hídrica mundial por setores produtivos Fonte: Hoekstra e Chapagain, 2007)

A sustentabilidade de uma região é influenciada pela sua pegada hídrica, sendo que muitas vezes é praticado fundamentalmente baseado na geração de riquezas, o que negligencia os sistemas naturais que dão suporte à vida. De acordo com a Figura 2, a pegada hídrica dos EUA é de $2.480 \mathrm{~m}^{3} /$ ano per capita devido ao elevado consumo per capita e o alto consumo de produtos industriais, já o do Irã é de $1.624 \mathrm{~m}^{3} /$ ano per capita devido sua baixa produção de produtos agrícolas, bem como pelas elevadas taxas de evapotranspiração. Outra 
importante informação é que nos EUA o componente industrial da pegada hídrica é de 806 $\mathrm{m}^{3}$ /ano per capita, já o Irã é de apenas 24 m³/ano per capita (GIACOMIN; OHNUMA, 2012). Na Figura 1 a cor verde significa que a pegada hídrica da nação é igual ou menor do que a média global; a cor vermelha mostra que o país tem uma pegada hídrica acima da média global.

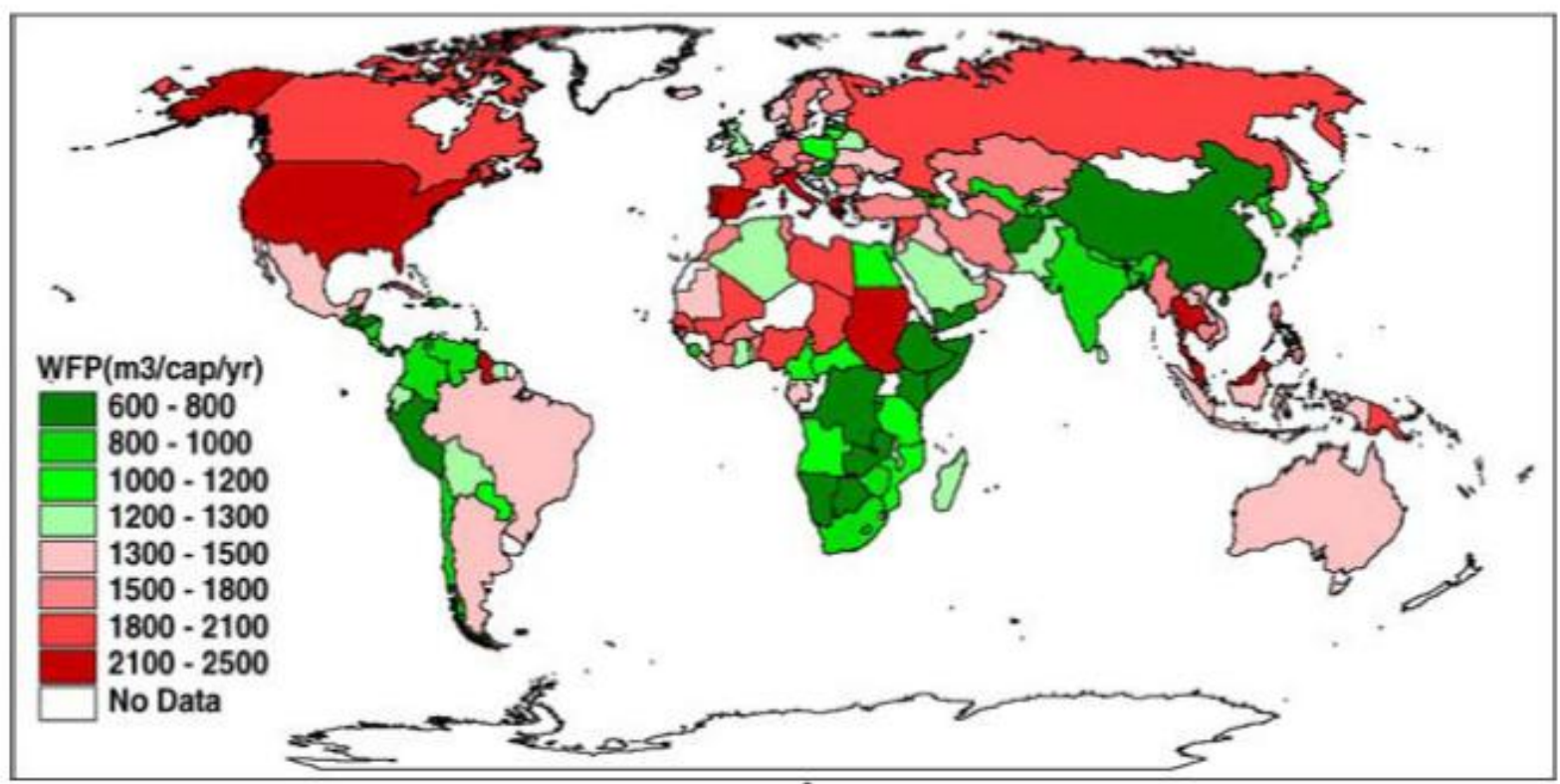

Figura 2. Pegada hídrica mundial per capita $\left(\mathrm{m}^{3} / \mathrm{ano}\right)$ Fonte: Hoekstra e Chapagain, 2007.

Nos países desenvolvidos, normalmente ocorre um maior consumo de bens e serviços, aumentando, assim, a pegada hídrica; já nos países subdesenvolvidos, às vezes ocorre uma combinação de condições climáticas desfavoráveis devido a alta evaporação e uma má prática agrícola resultando em baixa produtividade, obtendo com isso uma elevada pegada hídrica (GIACOMIN; OHNUMA, 2012). Por outro lado, é evidente a pressão que vem sendo praticada nos reservatórios de água doce devido à excessiva retirada desse recurso, bem como a poluição decorrente das atividades humanas. Hoekstra et al. (2011) destacam que o consumo total de água e a poluição são considerados como sendo a soma de várias demandas independentes de uso de água e suas atividades poluentes. Assim, cabe destacar que no passado a comunidade científica e as práticas de gestão tinham como base a quantificação do consumo da água ao longo de sua produção e de sua cadeia de suprimentos. Isso resultava em pouca consciência quanto ao fato de que a organização, assim como a característica de uma cadeia de produção e fornecimento, influencia o consumo de água e a poluição que hoje podem ser associados ao produto final.

No ano de 2002, o pesquisador Arjen Hoekstra criou o modelo da pegada hídrica que visualiza o uso da água escondida nos produtos, ajudando assim a compreender o caráter global de água doce e a quantificação dos efeitos do consumo e do comércio sobre os recursos hídricos. Com o aumento populacional no planeta, os países começam a sofrer com a escassez de água, fazendo-se necessária a máxima racionalização da sua utilização dos recursos hídricos (LIU; SAVENIJE et al., 2008). Desse modo, a quantificação do uso direto de água 
doce para elaboração de um produto ou apenas para suprir a necessidade de um consumidor, deve-se quantificar o uso indireto necessário ao longo de toda a cadeia produtiva ou todos os processos até que um produto ou serviço possa ser utilizado (HOEKSTRA; CHAPAGAIN, 2008).

O volume de água doce utilizada para produzir o produto, somada ao longo das várias fases da cadeia de produção, é a base para a compreensão do conceito de pegada hídrica. Desse modo, a PH pode ser considerada como um indicador compreensivo da apropriação do recurso de água doce, confrontando a tradicional e restrita mensuração de retirada de água. Partindo desse princípio, a PH do indivíduo ou comunidade se divide em três componentes: azul, verde e cinza. A PH foi definida baseada no uso real da água por unidade de consumo, logo ela só pode ser calculada através da análise da fonte de bens de consumo; e assim, considerar o uso real da água nos países de origem, ou seja, onde a produção acontece.

Os indicadores de sustentabilidade utilizados pela PH se baseiam na apropriação da água de bens e serviços, integrando o uso da água e da poluição sobre a cadeia de produção, indicando a ligação entre o local e o consumo global dos recursos hídricos, aferindo-se não apenas o uso da água azul, mas também o uso da água verde e a produção da água cinza poluída. A PH difere da medida clássica de "água retirada" em três aspectos (HOEKSTRA et al., 2009): (i) ela não se restringe a utilização da água azul, mas também a água verde e azul; (ii) ela não é restrito ao uso da água, mas inclui o uso da água indireta, ou seja, a água do consumidor ou do produtor e (iii) ela não inclui o uso da água azul, na proporção que a água é devolvida de onde veio.

A PH, como foi dita anteriormente, pode ser calculada para um produto, um indivíduo, uma nação, etc., informando espacialmente e temporariamente os volumes de água doce utilizadas nas cadeias produtivas e de consumo humano; destacando-se, assim, o país onde foi produzida a commodity e a duração de todo o ciclo da produção até o destino final.

\subsection{Tipos de Pegadas Hídrica}

A PH azul é o indicador do consumo de água doce superficial e/ou subterrânea. Para Hoekstra et al. (2011) o termo "uso de água de consumo" refere-se a um dos quatro casos seguintes: (i) evaporação da água; (ii) água incorporada no produto; (iii) não retorno da água para a área de captação (água é retornada para outra área ou para o mar); e (iv) não retorno da água no mesmo período (água é retirada no período escasso e é retornada no período chuvoso). Por outro lado, nos dias atuais, o maior consumo global de água azul é o setor agrícola (SHIKLOMANOV, 2000). A PH verde é definida como sendo a água oriunda de precipitações que não é retirada e nem armazenada pelos mananciais, e sim é armazenada temporariamente no solo ou permanece temporariamente na superfície do solo ou vegetação (HOEKSTRA et al., 2011). Ela representa o volume de água proveniente de chuva consumida durante o processo de produção. $O$ cálculo da pegada hídrica verde é particularmente relevante para produtos baseados em culturas agrícolas devido à evapotranspiração.

A distinção entre a $\mathrm{PH}$ azul e verde é muito importante devido aos impactos hidrológicos, ambientais e sociais, assim como os custos e impactos do uso da água superficial e do sub-solo. Essa definição difere dos custos e impactos do uso de água de chuva (HOEKSTRA et al., 2011). A PH cinza indica o grau de poluição de água doce associada ao 
processo de produção. Hoekstra et al. (2009) define essa componente da PH como sendo o volume de água doce que é requerida para assimilar a carga de poluentes, baseando-se nas concentrações naturais e padrões de qualidade de água existentes. Ela é calculada dividindo-se a carga de poluentes pela diferença entre a máxima concentração aceitável para aquele poluente específico e sua concentração natural naquele corpo de água que assimila o poluente.

$\mathrm{Na}$ análise da sustentabilidade da pegada hídrica deve-se considerar não apenas o tamanho da pegada, mas principalmente o seu impacto em um determinado local. Desse modo, é possível fornecer uma orientação mais clara sobre quais partes da cadeia de abastecimento deve-se focar e como priorizar as ações ambientais. A sustentabilidade da pegada hídrica avalia os impactos na água doce ocasionados pelo consumo dos produtos; assim, a analisa a "água embutida" nos produtos, ou seja, a água usada na sua cadeia de fornecimento e fabricação. Essa informação pode ajudar quantificar e reduzir os gastos da água doce.

De acordo com o manual de sustentabilidade da Coca-Cola (SAPIRO, 2011), quase um bilhão de pessoas necessitam de água potável nos dias atuais e se esses padrões de consumo continuarem, cerca de dois terços da população mundial viverá sem água limpa até 2025. Cabe destacar que a agricultura desempenha um papel fundamental nesse cálculo, visto que 70 por cento da água doce retirada pelos seres humanos é destinada a agricultura irrigada, enquanto a agricultura como um todo corresponde a 86 por cento do uso da água em todo o mundo. A avaliação do indicador de sustentabilidade da pegada hídrica de um produto tem que considerar os aspectos globais e locais, visto que os recursos hídricos variam drasticamente de um local para outro.

O uso eficiente e sustentável da água doce na produção de alimentos é fundamental para se alcançar um abastecimento seguro e consciente para toda a população mundial. Como exemplo pode-se citar que a pegada hídrica na produção da saca da beterraba na Espanha é menor do que na Romênia (SAPIRO, 2011). Assim, o quê é "melhor" para o meio ambiente? A menor pegada hídrica por $\mathrm{kg}$ de determinado produto não é necessariamente o mais sustentável. A grande questão nessa problemática é se a produção e a cadeia de abastecimento de um determinado produto utiliza a água de forma sustentável e equilibrando em todo o processo de utilização. No exemplo mencionado da beterraba, após a contabilização da pegada hídrica, deve ser determinado o impacto da pegada hídrica da saca em nível regional para depois ser feito um relato de indicador de sustentabilidade desse local. Deste modo, a avaliação da sustentabilidade ocorre a nível local, devido as alterações do clima, solo, escassez de água, etc.

Sobre os impactos referentes à exploração dos recursos hídricos em termos de quantidade ou qualidade, deve-se ser feita uma análise dos impactos causados sendo eles avaliados de acordo com seu caráter primário ou secundário. Como impactos primários entende-se que vão comprometer os requisitos de fluxo ambientais (isto é, os fluxos fluviais sustentáveis para os ecossistemas e para a vida humana), ou para os padrões de qualidade do ambiente da água. Os impactos secundários podem incluir ausência de água potável, perda de biodiversidade e de outros fatores ecológicos, econômicos, sociais e ambientais (SAPIRO, 2011). Assim, para se avaliar os indicadores de sustentabilidade levando em consideração os impactos primários e secundários devem ser considerdas algumas questões chaves, como o uso da água azul (quantidade de água) e água cinza (qualidade de água). Já a análise sobre a 
água verde (evapotranspiração) ainda não teve nenhuma abordagem científica concluída que pudesse respaudar uma análise para esse trabalho. Nesse aspecto, o grupo de pesquisa Pegada Hídrica Brasil (www.dca.ufcg.edu.br/phb) se encontra realizando uma pesquisa para a mensuração da pegada hídrica da cana-de-açúcar, com detalhamento quantitativos das componentes azual, verde e cinza da $\mathrm{PH}$.

Para o impacto da pegada azul é feita a medição através dos fluxos dos rios, que incluem águas superficiais e subterrâneas. Também é feita uma investigação sobre os problemas de água daquela localidade relacionados à sociedade, meio ambiente e a economia; desse modo ocorre também uma avaliação secundária onde os impactos primários da pegada hídrica são encontrado. Desse modo, a sustentabilidade regional depende das questões de cunho produtivo da localidade analisada e de um determinado produto; sendo assim, justificada a partir da pespectiva global da disponibilidade de água doce e solo fértil naquele local.

\subsection{Uso sustentável da água}

De acordo com Hoekstra e Chapagain (2008), no livro Globalization of Water, não é possível trabalhar apenas com um único indicador de sustentabilidade, por causa da enorme variedade de fatos, valores e incertezas no debate sobre o desenvolvimento sustentável da água. Deste modo, a pegada hídrica de uma nação não deve ser vista como o indicador final do debate sobre sustentabilidade, devido cada cidade possuir suas diversidades de fatores que irão interferir no cálculo final dessa pegada. Os indicadores anteriores do uso da água, tinham a perspectiva apenas do consumidor sobre o uso da água, enquanto deveriam ter também a análise na perspectiva do produtor.

Na década de 1990 surgiu o conceito de pegada ecológica como sendo a determinação da área de terra necessária para suprir as necessidades de uma dada população, sem que exista prejuízo ao ecossistema, levando em consideração a área necessária para se atender um sistema populacional urbano (a partir dos níveis de consumo, do desenvolvimento de novas tecnologias, da importação e exportação de produtos, da eliminação de espécies concorrentes, da eficiência da produção e da administração dos recursos naturais) (Carvalho \& Maracajá, 2010). No entanto, vários estudiosos têm dúvidas sobre se esse conceito é útil na ciência e/ou na política. Ao mesmo tempo, o conceito de pegada ecológica atrai a atenção do universo acadêmico e inúmeras pesquisas começam a ser feitas. Deste modo, Hoekstra \& Chapagain (2008) descrevem que o conceito de pegada hídrica adiciona uma nova perspectiva em relação à escassez de água, à dependência da água, ao uso sustentável da água, e às implicações da gestão global do comércio virtual da água.

A pegada hídrica têm como mostrar a utilização da água em todos os países e cidades, demonstrando como deve ser utilizado esse recurso de maneira mais sustentável. Os problemas de água nas principais áreas produtoras de algodão não pode ser resolvido sem que seja abordado a questão global, visto que os consumidores não podem ser totalmente responsáveis por todos os custos econômicos e pelos impactos ecológicos do seu consumo de algodão, que permanecem nas áreas produtoras (Chapagain et al., 2006). Assim, a pegada hídrica mostra o uso da água do ponto de vista do consumidor, enquanto as estatísticas tradicionais mostram o uso da água do ponto de vista do produtor. Então, se torna possível 
comparar a demanda de água para as pessoas na África ou país asiático, simplesmente porque o uso da água informa sobre a produção mas não sobre o consumo.

É importante destacar que a pegada hídrica mostra através de suas diversas pesquisas a dependência das nações sobre os recursos hídricos de outros países. Por exemplo, para o consumo de produtos de algodão, a União Européia é dependente dos recursos hídricos de outros continentes, particularmente da Ásia, mas há também uma forte dependência de recursos hídricos estrangeiros para outros produtos. Iisso significa que a água na Europa é mais escassa do que os indicadores atuais sugerem.

Para Hoekstra e Chapagain (2007), no trabalho publicado sobre a pegada hídrica das nações, o algodão é responsável por 2,6\% do uso global da água. Assim, por ser um média global, $44 \%$ do uso da água para o cultivo do algodão e seu processamento não é para o mercado interno, mas sim para a exportação. Para $1 \mathrm{~kg}$ de algodão são necessários 10.000 litros de água. Isso significa que cerca da metade dos problemas de água em todo o mundo está relacionada com os produtos de algodão. Desse modo, ao olhar para as relações comerciais, é possível encontrar a localização da pegada hídrica de uma comunidade ou, de outra forma, relacionar com o consumo em um lugar ocorrendo os impactos em outros lugares. Os cálculos mostram que os consumidores na União Européia indiretamente contribuem com cerca de $20 \%$ para a dessecação do Mar de Aral.

Identificar a ligação entre os consumidores de algodão e os impactos sobre os recursos naturais na produção do algodão é uma questão relevante, tendo em vista o fato de que os impactos econômicos e ambientais do uso da água geralmente não são incluídos no preço pago pelos consumidores estrangeiros. Isso é, portanto, um aspecto extremamente relevante na política que visa à redução dos impactos negativos, tais como o esgotamento da água e da poluição.

Cada componente da pegada hídrica total inclui um custo econômico e um impacto ambiental que seria de extrema importância ser acrescido a empresa que está produzindo aquele produto para o consumidor, e não apenas o consumidor ter que arcar com todo o custo. Os impactos sociais e ambientais do uso da água em geral não são traduzidos para o preço de todos os produtos, com exceção, às vezes dos custos de tratamento de efluentes antes do descarte. A maioria dos fluxos de resíduos globais não são tratadas. Embora alguns países industrializados possam alcançar uma cobertura de tratamento de efluentes de quase $100 \%$, tal cobertura permanece abaixo de 5\% na maioria dos países em desenvolvimento (Hoekstra, 1998). Além disso, a cobertura do tratamento de $100 \%$ em alguns dos países industrializados se refere ao tratamento de fluxos de resíduos concentrados em indústrias e em famílias, mas exclui o fluxo de resíduos da agricultura.

Cerca de um quinto da pegada hídrica global, devido ao consumo de algodão, está relacionado com a poluição. Essa estimativa é baseada na suposição de que os fluxos de águas residuais pode ser traduzido em uma exigência de água certa para a diluição com base em padrões de qualidade da água. A maioria dos fluxos de resíduos entre corpos de água naturais sem tratamento ocorre por causa da lixiviação de fertilizantes na agricultura e em grande parte pelos fluxos de resíduos das indústrias de algodão.

Em alguns países ricos, no entanto, os fluxos de resíduos industriais são muitas vezes tratados antes do descarte. No caso do tratamento de fluxos de resíduos, na medida em que os efluentes satisfazem as normas de qualidade da água, uma melhor estimativa para a exigência 
de água seria a de considerar a utilização de água real para o processo de tratamento. Outra questão importante é que não se conta as concentrações de fundo naturais na água de diluição, o que significa que estimativa para o volume de diluição necessária é conservador. $\mathrm{O}$ fato de se analisar o volume de diluição necessária para fertilizantes, mas não o volume para diluir os pesticidas utilizados, também são estimativas totalmente conservadoras (Hoekstra et al., 2001).

\section{CONSIDERAÇÕES FINAIS}

A escassez da água doce está intrinsecamente ligada ao consumo e produção de bens de consumo de forma desordenada pela população. Neste contexto, a pegada hídrica pode ser utilizada como indicador de sustentabilidade ambiental, haja vista que o seu conceito incorpora o conceito do uso direto e indireto de água doce utilizada nos bens de consumo.

A falta de dados específicos sobre certas culturas, como necessidade hídrica, data de cultivo e o ciclo de vida da planta, impossibilita a avaliação de sustentabilidade da pegada hídrica em alguns países. Porém, pesquisas devem ser realizadas em cooperação com parceiros comerciais nacionais e intenacionais a fim de se obter uma visão geral da situação da água doce no planeta e também avaliar os impactos de pegada hídrica das commodities agrícolas a nível das bácias hidrográficas. As questões como a irrigação eficiente ou a redução do uso de fertilizantes no campo podem minuimizar os impactos locais da pegada hídrica. Algumas empresas já estão começando suas próprias investigações para reduzir os impactos da pegada hídrica em seus produtos, como a coca-cola e a Natura.

Para que seja reduzida a pegada hídrica, primeiro se deve adotar técnicas de produção que exijam uma menor quantidade de água doce por unidade de produto. Por outro lado, em se tratando da agricultura devem ser aplicadas novas técnicas para captação da água da chuva e de irrigação suplementar. Uma outra maneira de reduzir a pegada hídrica seria uma mudança nos padrões de consumo da população, optando por produtos que exijam uma menor quantidade de água.

O preço do produto associado ao consumo de água pode ser forte inluenciador na redução da pegada hídrica porque os padrões de consumo estão diretamente ligados ao seu valor; desse modo, a conscientização da população pode ser alcançada com a rotulagem dos produtos, informções ou incentivos diversos que façam as pessoas mudarem seus hábitos de cosumo.

A redução da pegada hídrica também pode ser vista através do aumento de preço da água nas cidades e nas agroindústrias diminuindo, assim, o consumo, provocando o uso mais eficiente da água. Outra alternativa que poderia ser adotada pelo governo seria um plano de incentivo para as empresas e pessoas que estão fazendo o reúso da água, além de adotar uma maior divulgação de medidas sustentáveis que possam ser aplicadas no dia-a-dia da população que, como resultado, irá gerar um menor custo econômico e, consequentemente, uma menor pegada hídrica. A redução da pegada hídrica e a implementação desse indicador de sustentabilidade ambiental para avaliação do consumo da água doce podem ser um instrumento de planejamento de políticas sociais, econômicas e ambientais. Destaca-se, também, a adoção de uma legislação voltada para o uso responsável da água, com vistas a 
redução de consumo e poluição como forma de garantir a preservação desse recurso natural para as gerações futuras.

\section{REFERÊNCIAS}

CHAPAGAIN, A. K.; HOEKSTRA, A. Y., SAVENIJE, H. H. G.; GAUTAM, R. The water footprint of cotton consumption: An assessment of the impact of world worldwide consumption of cotton products on the water resources in the cotton producting countries. Ecological economics, v. 1, n. 60, 2006, pp. 186-203.

CARMO, R. L.; OJIMA, A. L. R. O; OJIMA, R; NASCIMENTO, T. T. Água virtual, escassez e gestão: O Brasil como grande "exportador" de água. Revista Ambiente \& Sociedade, v.10, n.1, 2007, pp. 83-96.

CARVALHO, J. R. M. de; MARACAJÁ, K. F. B. Ecological Footprint Method: análise da sustentabilidade ambiental no estado da Paraíba. Revista Querubim, v.3, n.12, 2010, pp. 27-36.

ERCIN, A. E.; ALDAYA, M. M.; HOEKSTRA, A. Y. Corporate water footprint accounting and impact assessment: the case of the water footprint of sugar-containing carbonated beverage, Water Resources Management, v. 25, 2011, pp. 721-741.

FENG, K.; SIU, Y. L.; GUAN, D.; HUBACEK, K. Assessing regional virtual water flows and water footprints in the Yellow River Basin, China: A consumption based approach. Applied Geography, v. 32, 2011, pp.691-701.

GIACOMIN, G. S.; OHNUMA, A. A. A pegada hídrica como instrumento de conscientização ambiental. REMOA-UFSM, v. 7, n.7, mar./jun., 2012, pp. 1517-1526.

GLEICK, P. H. The changing water paradigm: a look at twenty-first century water resources development. Water International, v. 25, 2000, pp.127-138.

HOEKSTRA, A. Y. Perspectives on water: a model-based exploration of the future. International Books, Utrecht, 1998.

HOEKSTRA, A. Y. The water footprint of animal products. In: J. D' Silva and J. Webster (eds) The Meat Crisis: Developing More Sustainable Production and Consumption, Earthscan, London, 2010, p. 22-33.

HOEKSTRA, A.Y.; CHAPAGAIN, A. K. Water footprints of nations: water use by people as a function of their consumption pattern, Water resources Management. 21(1), 2007, pp.3548. 
HOEKSTRA, A. Y.; CHAPAGAIN, A. K. Globalization of water: sharing the Planet"s freshwater resources. 1. ed. Oxford: Blackwell Publishing, 232p., 2008.

HOEKSTRA, A. Y.; HUNG, P. Q. Globalization of water resources: international virtual water flows in relation to crop trade. Global Environmental Change, v. 15, p. 45-56, 2005.

HOEKSTRA, A. Y.; CHAPAGAIN, A. K.; ALDAYA, M. M.; MEKONNEN, M. M. The water footprint manual: State of the art. 1.ed. Enschede: Water Footprint Network, 2009, p.127.

HOEKSTRA, A. Y., CHAPAGAIN, A. K.; ALDAYA, M. M.; MEKONNEN, M. M. The water footprint assessment manual. 1.ed. London: Water Footprint Network, pp. 224, 2011.

HOEKSTRA, A. Y., SAVENIJE, H. H. G., AND CHAPAGAIN, A. K. An integrated approach towards assessing the value of water: a case of study on the Zambezi basin. Integrated assessment, v.4, n.2, 2001, pp. 199-208,.

Liu, J., Savenije, H. G. Food consumption patterns and their effect on water requirement in China. Hydrology and Earth System Sciences, v. 12, p. 887-898, 2008.

MARTINS, G. de A., THEÓPHILO, C. R. Metodologia da investigação científica para ciências sociais aplicadas. 2 ed. São Paulo: Atlas, 2009.

PEGADA HÍDRICA BRASIL. Conceitos. Disponível em: <http://www.dca.ufcg.edu.br/phb/phb02.html>. Acesso em 14 de julho de 2012.

PERRY, C. Efficient irrigation; inefficient communication; flawed recommendations, Irrigation and Drainage, v. 56, 2007, pp. 367-378,.

ROMAGUERA, M., HOEKSTRA, A. Y., SU, Z.; KROL, M. S., SALAMA, M. S. Potencial of using remote sensing techniques for global assessment of water footprint of crops. Journal, Remote Sensing, v. 2, 2010, pp. 1177-1196.

SAPIRO, U. Towards sustainable sugar sourcing in Europe. Water footprint sustainability assessment (WFSA), August 2011.

SHIKLOMANOV, I. A. Appraisal and Assessment of word water resources. Water International, v. 25, 2000, pp. 11-32.

SILVA, V. P. R.; SOUSA, F. S. S.; CAVALCANTI, E. P.; SOUZA, E. P.; SILVA, B. B. Teleconnections between sea-surface temperature anomalies and air temperature in northeast Brazil. Journal of Atmospheric and Solar-Terrestrial Physics, v. 68, p. 781 - 792, 2006. 
VAN OEL, P. R., MEKONNEN, M. M., HOEKSTRA, A.Y. The external water footprint of the Netherlands: Geographically-explicit quantification and impact assessment. Ecological Economics, v. 69, p.82-92, 2009.

ZHAO, X., CHEN, B., YANG, Z. F. National water footprint in an input-output frameworkA case study of China 2002. Ecological Modeling, v. 220, p.245-253, 2009.

YANG YU, Y., HUBACEK, K., FENG, K. GUAN, D. Assessing regional and global water footprints for the UK. Ecological Economics, v.69, 2010, pp. 1140-1147. 